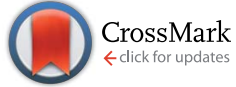

Cite this: J. Mater. Chem. A, 2015, 3, 10864

Received 18th February 2015 Accepted 10th April 2015

DOI: $10.1039 / \mathrm{c} 5 \mathrm{ta0} 1337 \mathrm{~b}$

www.rsc.org/MaterialsA

\section{Novel phosphoric acid-doped PBI-blends as membranes for high-temperature PEM fuel cells}

\begin{abstract}
Florian Mack, ${ }^{a}$ Karin Aniol, ${ }^{b}$ Corina Ellwein, ${ }^{b}$ Jochen Kerres $^{* b c}$ and Roswitha Zeis ${ }^{a}$
Novel acid-base blend membranes for application in high-temperature polymer electrolyte membrane fuel cells (HT-PEMFCS) were synthesized and characterized. The acid-base blend membranes demonstrated high thermal and excellent chemical stabilities in terms of oxidative weight loss. Small changes in the molecular weight distribution after immersion in Fenton's solution were determined with gel permeation chromatography (GPC). Scanning electron microscope (SEM) images showed the outstanding integrity of the acid-base blend membranes after a 24 hour-long Fenton's test. In contrast to pure polybenzimidazole (PBI) and AB-PBI membranes the new acid-base membranes exhibited long-term stability in phosphoric acid (PA) at $130{ }^{\circ} \mathrm{C}$. Ionic cross-linking between acid and base blend polymers improved the stability and integrity of the membranes. The in situ conductivities of several acid-base blend membranes were higher than that of pure AB-PBI membranes with drastically reduced acid uptake. Membrane electrode assemblies (MEAs) based on these blend membranes were prepared showing good fuel cell performance at practical relevant operation conditions. This study proves that acid-base blends are a suitable alternative to pure PBI and AB-PBI as membranes for HT-PEMFCs.
\end{abstract}

\section{Introduction}

PA-doped PBI for use in HT-PEMFCs $\left(100-220^{\circ} \mathrm{C}\right)$ can be traced back to the work of Savinell et al. ${ }^{1}$ The advantage of PA-doped PBI membranes lies in the conductivity mechanism: in these membranes PA overtakes the proton transport instead of water ${ }^{2}$ which widens the temperature range of fuel cell membranes to the abovementioned temperature range, in which membranes which need water as a vehicle for $\mathrm{H}^{+}$transport (such as Nafion® or other sulfonated membranes) do not work anymore due to dry-out. A disadvantage of the PBI-PA composite membranes is the possible bleeding-out of PA from the membrane in cases where the operation temperature falls below $100{ }^{\circ} \mathrm{C}$, where condensed water flushes out PA from the membrane, ${ }^{3}$ as proven by in situ tests with neutron tomography. ${ }^{4}$ The operation limits of this membrane have been investigated by taking into account the PA bleeding-out problem. ${ }^{5}$ The so-released PA can cause strong corrosion damage within the fuel cell system.

A further disadvantage of PA-doped PBI is the chemical degradation of the polymer in the fuel cell, ${ }^{6}$ which is mainly relevant in the temperature range $150-200^{\circ} \mathrm{C}$, which is required for minimizing of carbon monoxide (CO) poisoning of the anode catalyst.

${ }^{a}$ Karlsruhe Institute of Technology (KIT), Helmholtz Institute Ulm (HIU), Ulm, Germany

${ }^{b}$ University of Stuttgart, Institute of Chemical Process Engineering, University of Stuttgart, Stuttgart, Germany.E-mail: jochen.kerres@icvt.uni-stuttgart.de

${ }^{c}$ North-West University, Potchefstroom Campus, Chemical Resource Beneficiation, Potchefstroom, South Africa
Within the last decade several approaches have been investigated to improve the stability of PBI. Strategies include the preparation of base-excess acid-base blend membranes of PBI with acidic polymers in which the acidic blend component acts as macromolecular ionic cross-linker for the blend membrane by proton transfer from the acidic group onto the basic imidazole sites of the PBI. Such membranes have been a research and development topic in the group of one of the authors of this study for more than a decade. ${ }^{7}$

It could be shown that the base-excess acid-base PBI blend membranes exhibit better chemical stabilities than pure PBI membranes as determined by Fenton's test (FT), where the membranes are subjected to oxidative treatment with an aqueous $3 \% \mathrm{H}_{2} \mathrm{O}_{2}$ solution also containing $4 \mathrm{ppm}$ of $\mathrm{Fe}^{2+}$ ions, which catalyze the decay of $\mathrm{H}_{2} \mathrm{O}_{2}$ into $\mathrm{OH}^{-}$radicals that attack the polymer chains. ${ }^{8,9}$ It could also be shown that the introduction of ionical cross-links into the PBI membranes can prevent them from dissolution in PA during the doping procedure. ${ }^{\mathbf{1 0}}$

In the study presented here novel PBI-excess acid-base blend membranes have been investigated in terms of their chemical stabilities and in terms of their performance in an HT-PEMFC at an operation temperature of $160{ }^{\circ} \mathrm{C}$. The different polymer compounds forming the PBI-blend membranes are depicted in Fig. 1. In Table 1 , the composition of the different blend membranes, their thickness and type of crosslinking are shown.

In Fig. 2, the covalent cross-linking at the blend membrane MJK1844 is shown, and in Fig. 3 the ionical cross-linking at the base-excess acid-base blend membranes at the example of the membrane MJK1845. 


\section{acidic polymers}
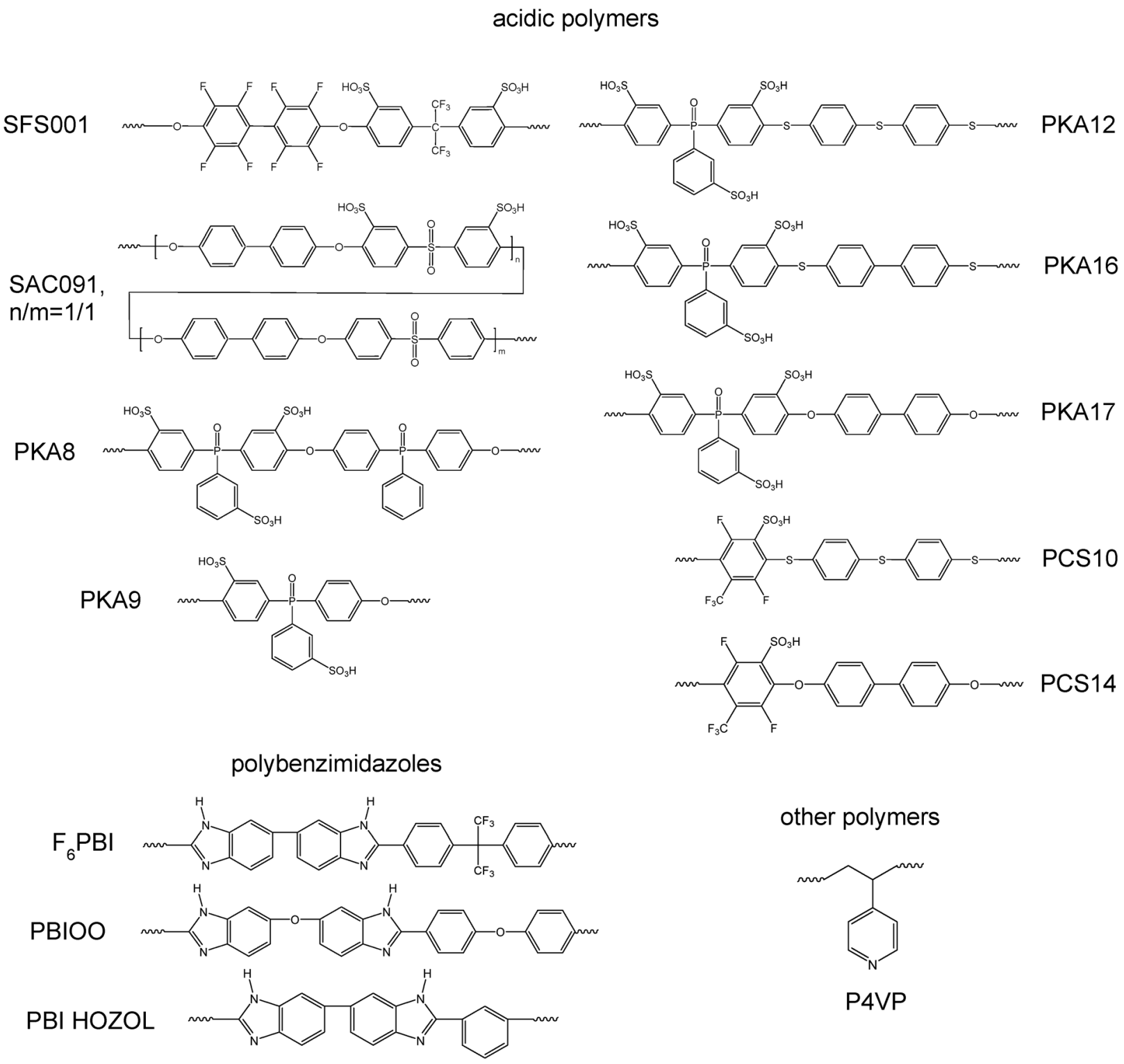

other polymers

Fig. 1 Polymers used for the preparation of the blend membranes.

Table 1 Composition of the acid-base blend membranes

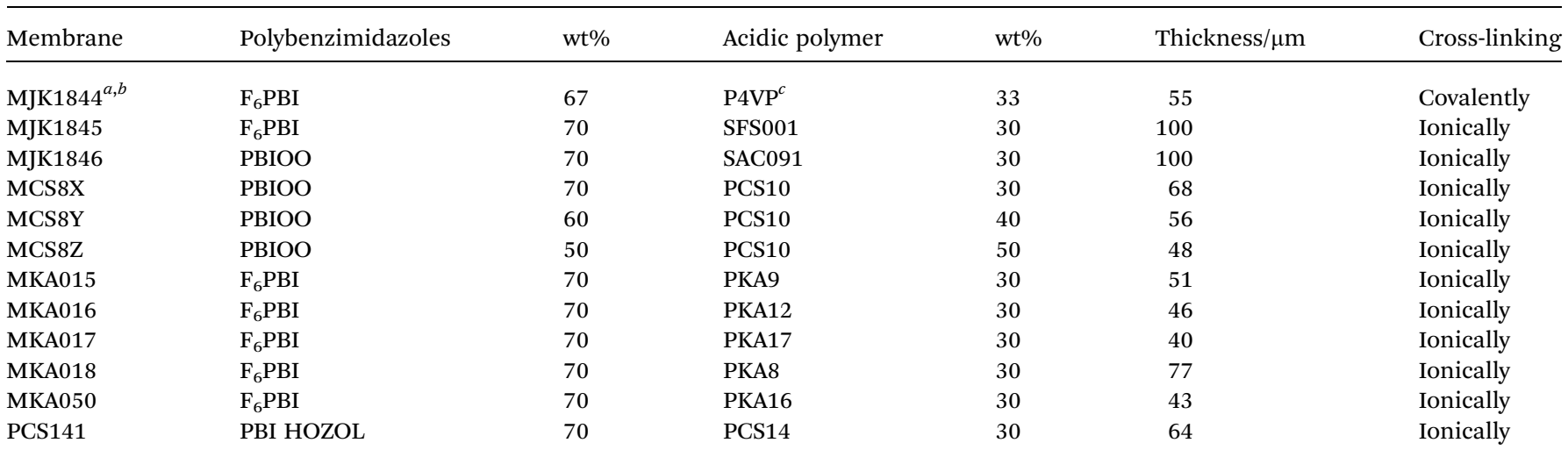

${ }^{a}$ Additive: diiododecane. ${ }^{b}$ Base-base blend membrane. ${ }^{c}$ Poly(4-vinylpyridine), basic polymer. 

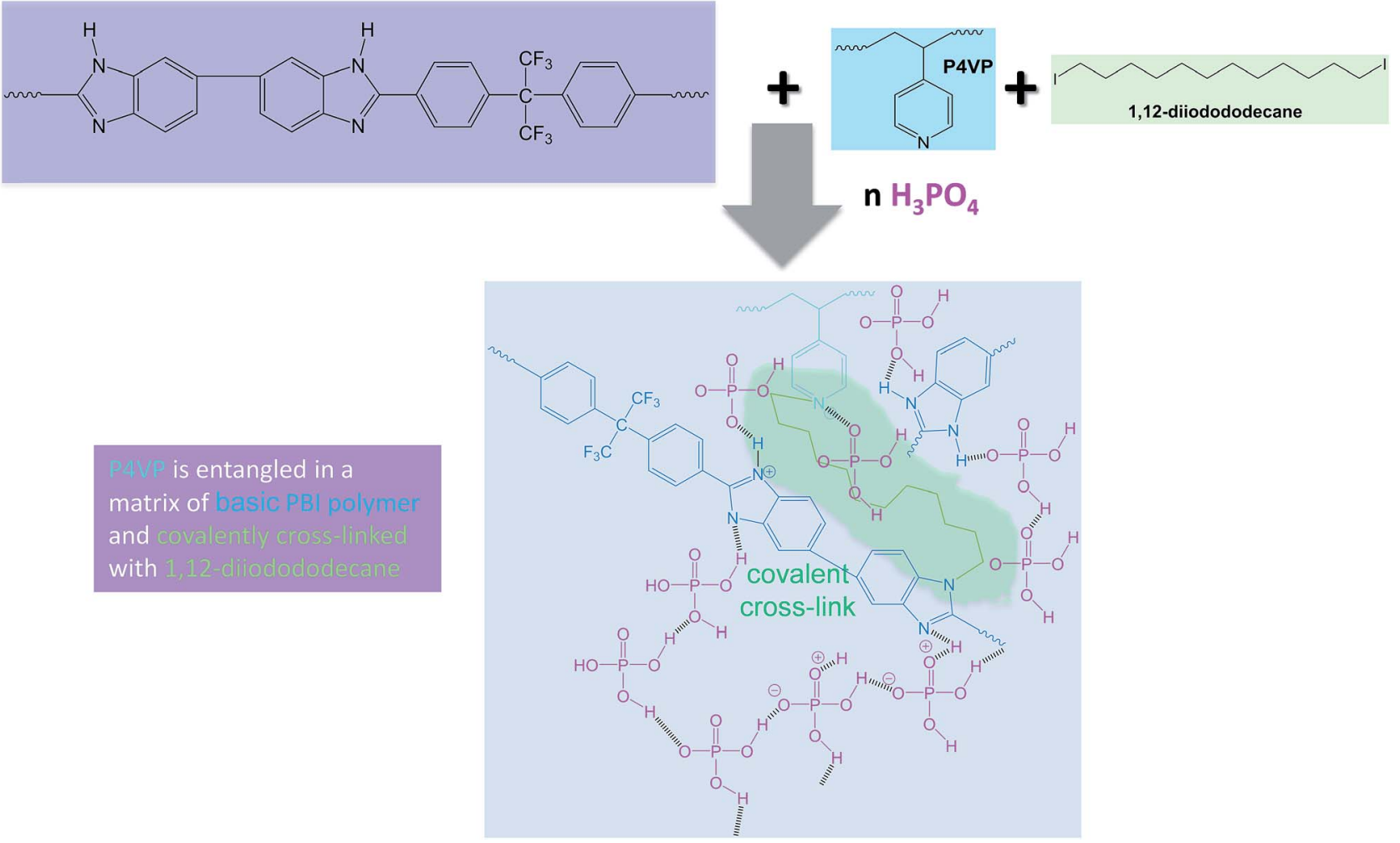

Fig. 2 Covalent cross-linking at the membrane MJK1844.
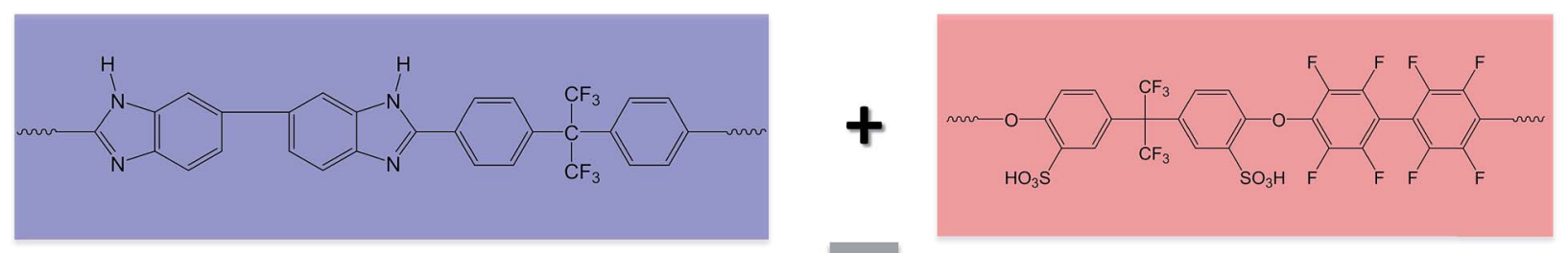

\section{n $\mathrm{H}_{3} \mathrm{PO}_{4}$}

Cation-exchange polymer is used as acidic macromolecular cross-linker for the basic PBI polymer

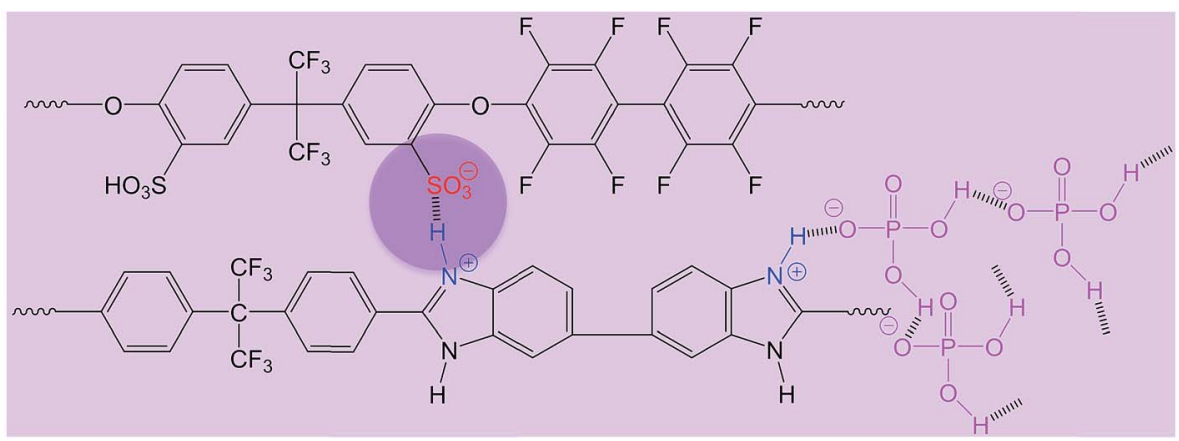

Fig. 3 lonical cross-linking and formation of the hydrogen bridge network by PA doping of the membrane MJK1845 as an example for the ionically cross-linked blend membranes. 


\section{Experimental}

\subsection{Thermal stability}

The thermal stability of the membranes was measured with thermogravimetry (TGA) using a Netzsch STA 449C Jupiter with a heating rate of $20 \mathrm{~K} \mathrm{~min}^{-1}$ under an oxygen enriched atmosphere (65-70\% oxygen, $30-35 \%$ nitrogen).

The decomposition gases were examined with a coupled FTIR spectrometer (Nicolet Nexus) to determine the start of the backbone degradation (CO evolution). The splitting-off temperature of the sulfonic acid group was identified through the asymmetric stretching vibration of the $\mathrm{S}=\mathrm{O}$ group at $1352-1342 \mathrm{~cm}^{-1}$.

\subsection{Oxidative stability}

The oxidative stability of the membranes was determined with FT. The undoped membranes were immersed in a Fenton's solution consisting of $3 \mathrm{wt} \%$ hydrogen peroxide containing $4 \mathrm{ppm} \mathrm{Fe}^{2+}$ (added as $\mathrm{FeSO}_{4}$ ) for a period of 24-144 hours at $68{ }^{\circ} \mathrm{C} .{ }^{8}$ Afterwards, the membrane samples were collected by filtering, washed with water, dried at $90{ }^{\circ} \mathrm{C}$ and weighed.

The molecular weight $\left(M_{\mathrm{W}}\right)$ distribution of the polymers was measured by GPC using an Agilent Technologies GPC system (series 1200) with a light scattering detector (static light scattering detector SLD7000) combined with a refractive index detector (Shodex RI71) for the concentration signal. $M_{\mathrm{W}}$ of the polymers was directly obtained from the light scattering detector signal. For the GPC analysis, $2 \mathrm{wt} \%$ solutions of the polymers in dimethylacetamide (DMAc) were prepared, and $5 \mathrm{~g} \mathrm{~L}^{-1} \mathrm{LiBr}$ was added to the polymer solutions prior to the measurements. Toluene was also added to the solvent to correct reversible changes in the column system. The molar mass distribution was measured with a constant flow rate of $1 \mathrm{ml}$ $\min ^{-1}$ at $60^{\circ} \mathrm{C}$.

The physical deterioration of the membranes was determined with SEM. Before the SEM measurements the samples were dried at $100{ }^{\circ} \mathrm{C}$ for $14 \mathrm{~h}$ and subsequently sputtered with gold for 3 minutes. The SEM pictures were obtained with a CamScan CS44 SEM.

\subsection{Membrane doping and electrode preparation}

The synthesis of the blend membranes was described previously. ${ }^{8}$ Commercial available AB-PBI membranes were purchased from Fuma-Tech (fumapem AM). The membranes were dried over night at $90{ }^{\circ} \mathrm{C}$ and afterwards their thickness was measured. Subsequently, the membranes were doped with PA by immersion in concentrated PA $\left(85 \%\right.$, Carl Roth) at $130{ }^{\circ} \mathrm{C}$ until their weight was constant. Additional PA on top of the membranes was removed with a paper towel before weighing. The amount of acid in the membranes was determined gravimetrically.

Catalyst suspensions (catalyst inks) containing water (Millipore), isopropanol, polytetrafluoroethylene (PTFE) solution $(60 \%, 3 \mathrm{M})$, and $20 \% \mathrm{Pt} / \mathrm{C}$ (Heraeus) were used for the gas diffusion electrode (GDE) preparation. The catalyst ink was sprayed in multiple layers directly onto the microporous layer of the gas diffusion layer (H2315 C2, Freudenberg) at a substrate temperature of $80^{\circ} \mathrm{C}$. The catalyst loading was kept constant at $1 \mathrm{mg} \mathrm{cm}{ }^{-2}$, which was calculated from the weight difference between the dried GDE and the gas diffusion layer. All the GDEs had approximately the same PTFE content of $10 \%$ by weight. The GDE preparation was described in detail previously. ${ }^{11}$

\subsection{Electrochemical characterization}

The membrane electrode assemblies (MEAs) were prepared by placing the GDEs in direct contact with the doped membranes in single cells without hot-pressing. The single cells with an active area of $4 \mathrm{~cm}^{2}$ included gaskets (PTFE from Bohlender), sub-gaskets (PEEK from Victrex), metallic bipolar plates with single serpentine flow-fields ( $1 \mathrm{~mm} \times 1 \mathrm{~mm}$ in dimension) and aluminum plates equipped with heating cartridges. The cell measurements were done at $160{ }^{\circ} \mathrm{C}$ and ambient pressure using dry hydrogen and air as reactants. Stoichiometric mass flows of hydrogen $(\lambda=1.4)$ and air $(\lambda=2)$ were used for current densities equal to or above $200 \mathrm{~mA} \mathrm{~cm} \mathrm{~cm}^{-2}$. Gas flows were fixed for current densities below $200 \mathrm{~mA} \mathrm{~cm} \mathrm{~cm}^{-2}$. Polarization curves were recorded by increasing the current density stepwise from zero (open circuit) up to $800 \mathrm{~mA} \mathrm{~cm} \mathrm{c}^{-2}$ or until the cell potential dropped below $300 \mathrm{mV}$. Cell internal resistances were determined by measuring AC impedances at $1 \mathrm{kHz}$ with an MR2212W impedance meter (Schuetz Messtechnik).

\section{Results and discussion}

\subsection{Thermal stability}

The thermal stability of the membranes was determined by TGA-FTIR-coupling to determine the starting temperatures for the separation of the sulfonic acid groups and the polymer backbone degradation ( $\mathrm{CO}$ evolution). The TGA traces of the acid-base blend membranes MJK1845 and MJK1846 in Fig. 4 show a similar behavior up to $400^{\circ} \mathrm{C}$ apart from an initial water loss of the MJK1846 membrane. The thermal stability of the base-base blend membrane MJK1844 was drastically lower. The acid-base blend membranes were stabilized by ionic crosslinking. ${ }^{9}$

A comparison of the onset temperatures of the $\mathrm{SO}_{3} \mathrm{H}$ splitting off and the backbone degradation of the membranes is presented in Table 2. The ionically cross-linked acid-base blend membranes demonstrate high thermal stability, especially the MCS and PCS membranes.

\subsection{Oxidative stability}

High chemical stability is a crucial requirement for fuel cell membranes. The oxidative stability of the membranes was tested with FT, and changes in the weight loss, the $M_{\mathrm{W}}$ distribution, and the physical properties of the membranes were determined. The most common degradation mechanism described in literature is the attack of the polymer chain by in situ formed hydroxyl and hydroperoxyl radicals. This leads to a reduction of the polymer weight ${ }^{9,12}$ and the breakdown of the polymer backbone into small pieces, which are dissolved in the Fenton's solution. ${ }^{13}$ 




Fig. 4 TGA traces of the MJK membranes.

Table 2 Onset temperatures of the $\mathrm{SO}_{3} \mathrm{H}$ splitting-off and the backbone degradation from the blend membranes

\begin{tabular}{lll}
\hline Membrane & $T_{\mathrm{SO}_{3} \mathrm{H}}{ }^{\circ} \mathrm{C}$ & $T_{\text {backbone }} /{ }^{\circ} \mathrm{C}$ \\
\hline MCS8X & 397 & 490 \\
MCS8Y & 410 & 481 \\
MCS8Z & 379 & 483 \\
MJK1844 & - & 262 \\
MJK1845 & 284 & 315 \\
MJK1846 & 304 & 407 \\
PCS141 $_{\text {PBI }^{14}}$ & 430 & 460 \\
& - & 500
\end{tabular}

An alternative mechanism is the separation of sulfonic acid groups. Both mechanisms drastically reduce the mechanical stability of the membranes which is crucial for fuel cell application.

3.2.1 Weight loss. The weight loss of the blend membranes in relation to the initial weight after immersion in the Fenton's solution for 24 hours and 144 hours is compared in Fig. 5. The base-base blend membrane MJK1844 was dissolved in the

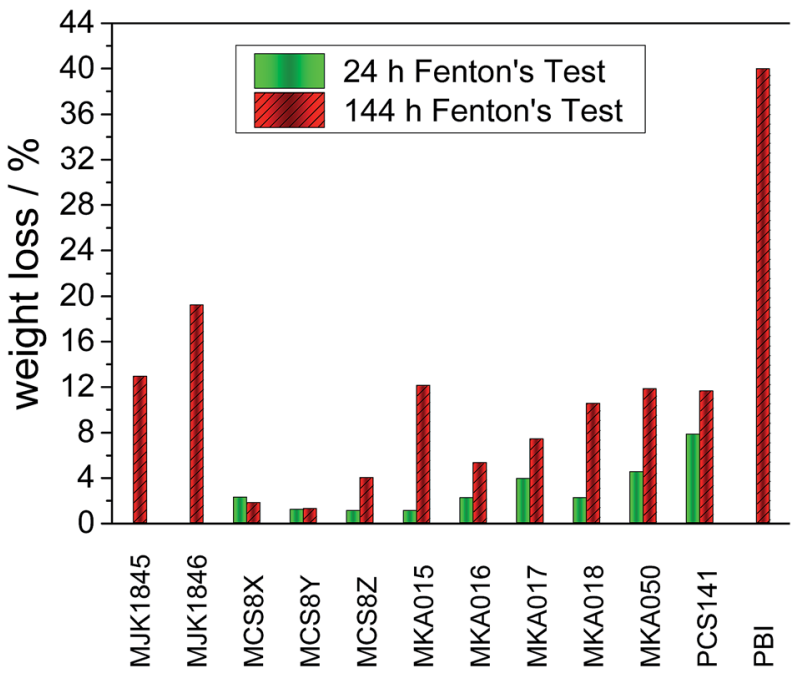

Fig. 5 Weight loss of the acid-base blend membranes and $\mathrm{PB}{ }^{20}$ after 24 and 144 hours Fenton test.
Fenton's solution. In contrast, the weight decrease of all tested acid-base blend membranes was below $8 \%$ after 24 hours and less than 20 wt\% after 144 hours FT. Especially the MCS membranes demonstrate a very high chemical stability with 2-4\% weight loss after 144 hours FT. The highest oxidative stability was achieved by the membrane MCS8Y consisting of $40 \%$ PCS10 and 60\% PBIOO.

The low weight loss of the MCS membranes can be explained with the partially fluorinated polymer PCS10 as acidic blend polymer. The binding energy of $\mathrm{C}-\mathrm{F}$ bonds is higher than for $\mathrm{C}-\mathrm{H}$ bonds, ${ }^{15}$ and PCS10 does not contain ether bridges, which are vulnerable to radical attacks. ${ }^{16}$ The pure basic blend polymers show a drastically higher stability than the pure acidic blend polymers. ${ }^{17}$ Therefore stable acidic polymers are crucial for robust blend membranes.

Compared to pure $\mathrm{PBI}^{\mathbf{1 8}}$ or $\mathrm{AB}-\mathrm{PBI}^{\mathbf{1 9}}$ membranes with weight losses of up to $80 \%$ all investigated acid-base blend membranes show drastically reduced weight losses during the FT. The crosslinking network improves the stability of the acid-base blend membranes which was already observed for other blend membranes. ${ }^{\mathbf{9 , 2 0}}$

3.2.2 $\boldsymbol{M}_{\mathrm{W}}$ distribution. The changes in the $M_{\mathrm{W}}$ distribution during the FT of the acid-base blend membranes were analyzed with GPC. The $M_{\mathrm{W}}$ distribution of the membranes MJK1845 and MJK1846 during FT was published previously, ${ }^{17}$ and the results of the membranes MCS8X, MCS8Z and PCS141 before and during the FT are shown in Fig. 6. The membrane MCS8Y was insolvable in the eluent after the FT, and this was attributed to temporary cross-linking by recombining polymer radicals.

The average $M_{\mathrm{W}}$ of the membrane MCS8X decreased after 24 hours FT; however it increased again after 144 hours FT. A possible explanation is the splitting of the polymer chains and the formation of polymer radicals during the first 24 hours FT, which led to a reduction of the $M_{\mathrm{W}}$. The polymer radicals remained in the membrane and recombined, which resulted in a higher $M_{\mathrm{W}}$ after 144 hours FT. An alternative explanation is the degradation of the polymer chains into smaller molecules which initially remain in the membrane and are gradually washed out with proceeding time in the Fenton's solution. After the dissolution of the smaller polymer pieces the average $M_{\mathrm{W}}$ increases again. The $M_{\mathrm{W}}$ loss of the membrane MCS8Z was 

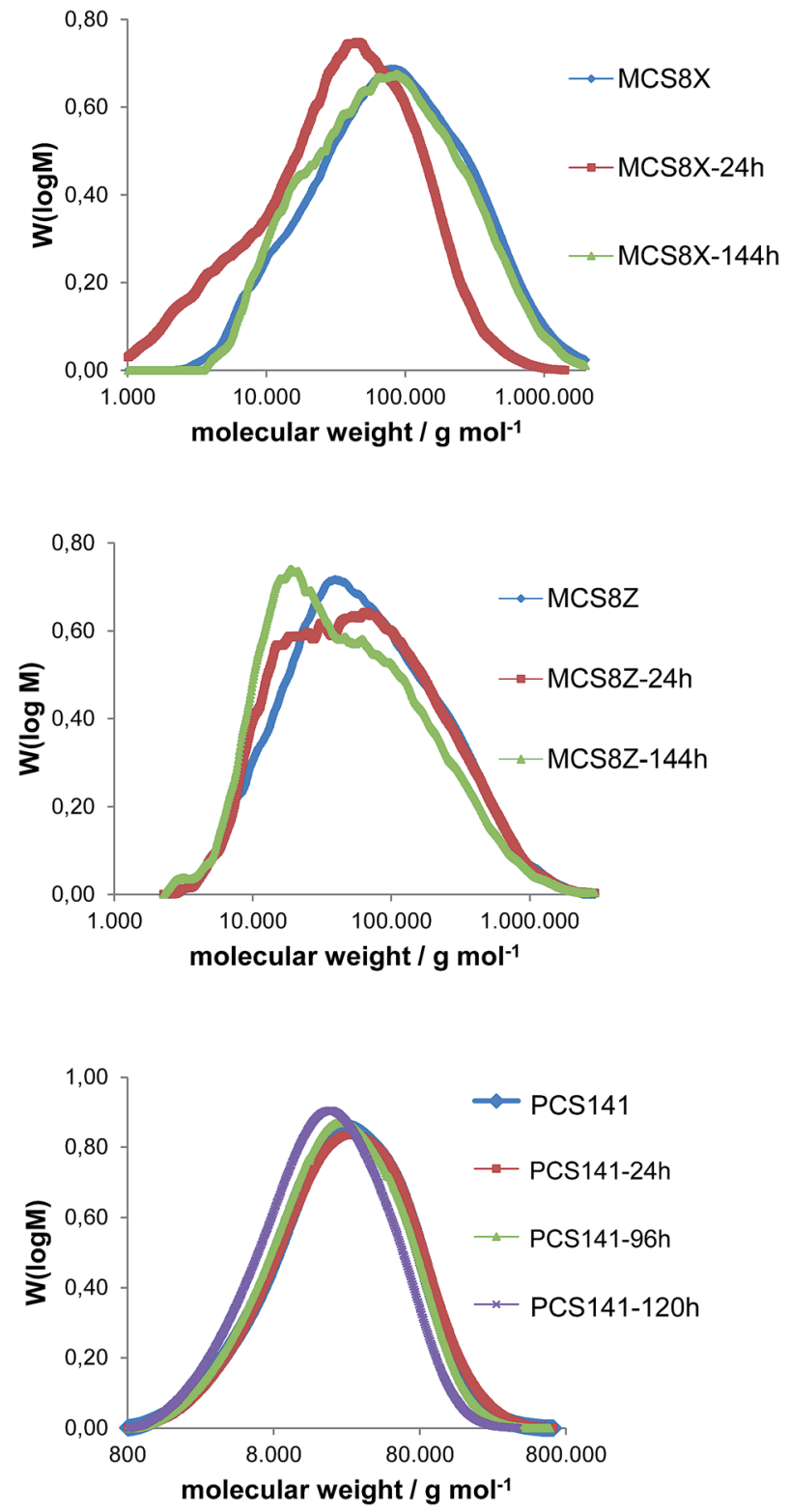

Fig. $6 M_{W}$ distribution of the membranes MCS8X, MCS8Z and PCS141 before and after different durations of Fenton test.

about $20000 \mathrm{~g} \mathrm{~mol}^{-1}$ after 144 hours FT, which is comparable to similar blend membranes ${ }^{9}$ and much lower than for pure PBIOO. ${ }^{17}$ The $M_{\mathrm{W}}$ distribution of the PCS141 membrane was almost constant during the first 96 hours FT and decreased slightly after 120 hours FT. The results of the GPC measurements from the MKA membranes are presented in Fig. 7 and compared with the initial $M_{\mathrm{W}}$ distribution of the basic blend polymer $\mathrm{F}_{6} \mathrm{PBI}$.

The average $M_{\mathrm{W}}$ of the MKA membranes strongly decreased during the first 24 hours FT and between 24 and 144 hours the $M_{\mathrm{W}}$ distribution was almost similar. The higher maximum of the $M_{\mathrm{W}}$ distribution curve is approximately at the same $M_{\mathrm{W}}$ as the maximum of the $M_{\mathrm{W}}$ distribution of pure $\mathrm{F}_{6}$ PBI. The degradation seems to be mainly focused on the acidic blend polymers. The basic polymer is quite resistant
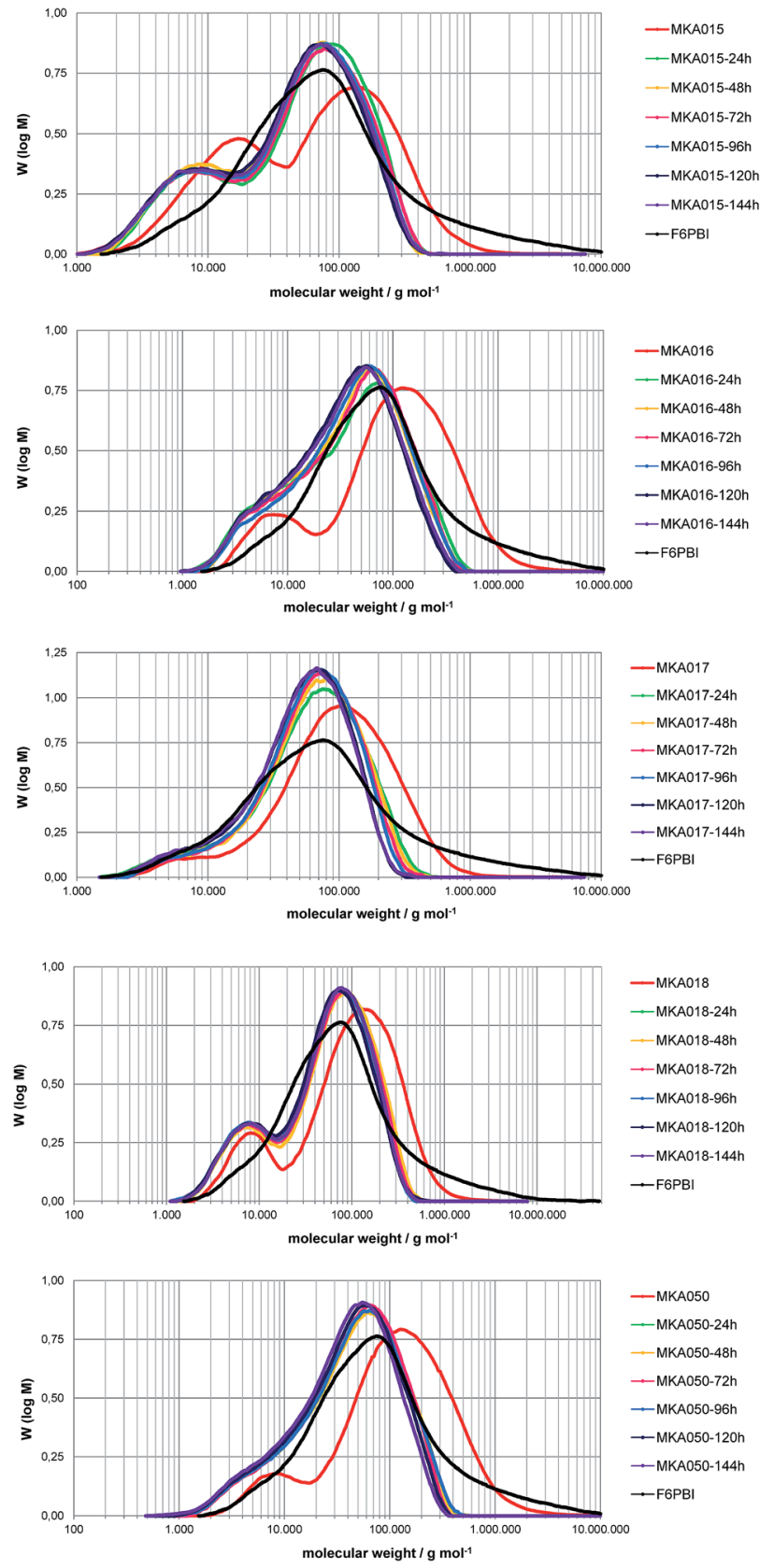

Fig. $7 M_{\mathrm{W}}$ distribution of the MKA membranes before and after different durations of Fenton test.

due to its very stable perfluoroisopropylidene bridges, ${ }^{21}$ the radical-trapping properties of the imidazole group ${ }^{9}$ and the ionic cross-linking network ${ }^{\mathbf{1 7}}$ which maintains the membrane integrity.

3.2.3 SEM images. The changes of the membrane surface during the FT were investigated with SEM. SEM micrographs of the membrane surfaces were obtained before and after 144 hours FT (Fig. 8). The untreated membranes showed a homogenous surface without holes which would appear as black spots in the SEM images. Brightness nuances and white spots were caused by the manual casting process of the membranes. 


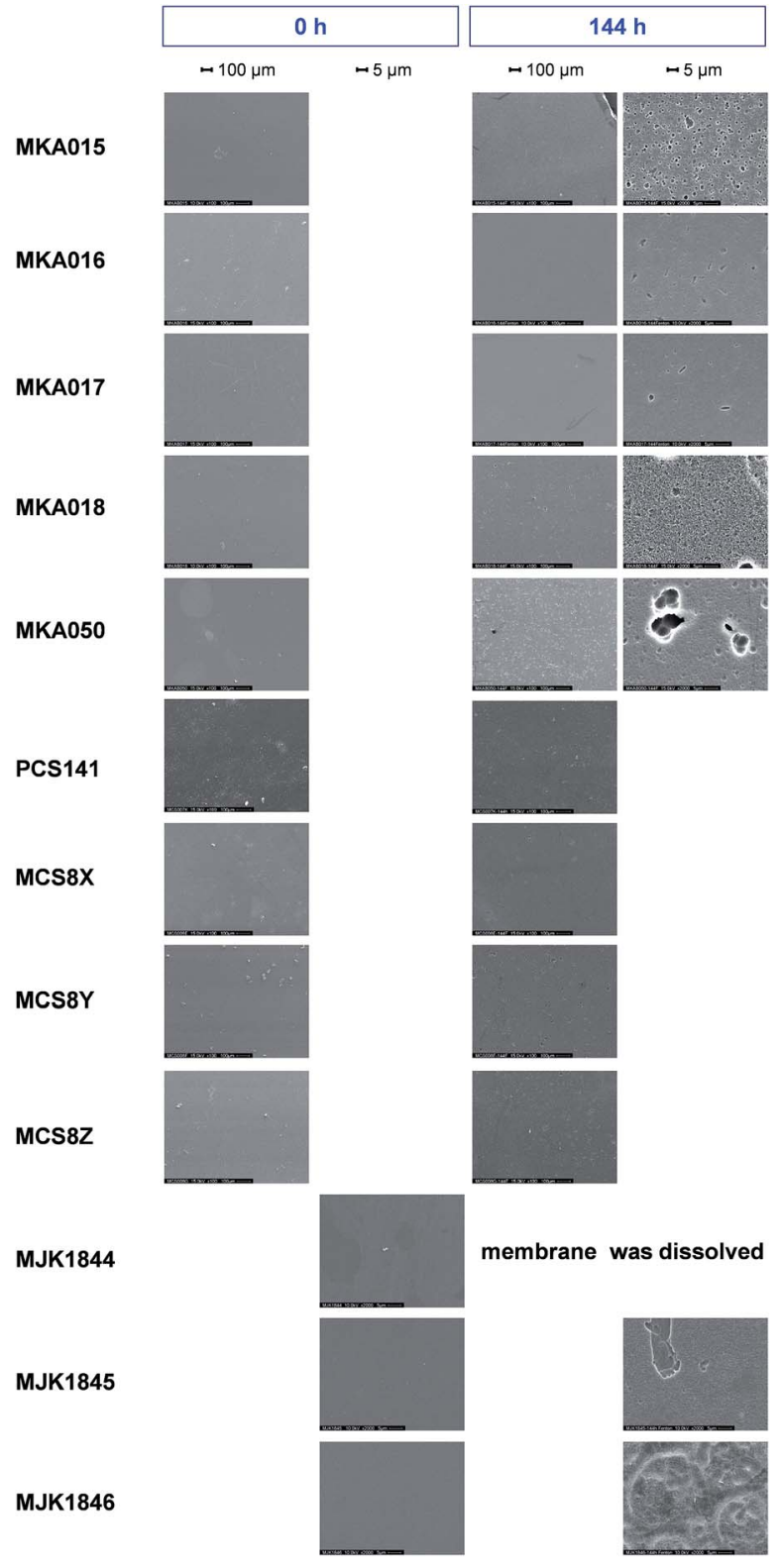

Fig. 8 SEM images of the membranes before and after 144 hours Fenton test; magnification $100 \times / 2000 \times$.

After 144 hours FT, the MJK1844 membrane was dissolved and the surfaces of the acid-base blend membranes exhibited small holes in the range of 1 to $5 \mu \mathrm{m}$ in diameter. Pure PBI membranes strongly degraded during the first 24 hours of FT and exhibited significant holes in the membrane in contrast to the blend membranes. ${ }^{13}$ AB-PBI membranes exhibited cracks over the whole membrane surface after 24 hours FT, and therefore demonstrated less chemical stability than the investigated acid-base blend membranes. ${ }^{19}$

\subsection{Acid uptake and doping time}

Pure PBI membranes can be doped by immersion in a concentrated aqueous PA solution at room temperature. After about 48 hours the equilibrium is reached with a doping level of

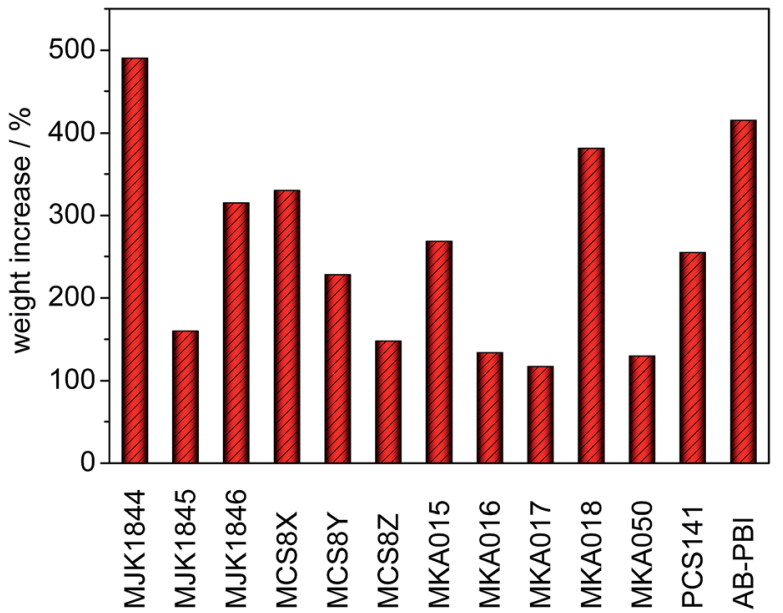

Fig. 9 Phosphoric acid uptake of the membranes by weight; $T=$ $130{ }^{\circ} \mathrm{C}\left(120{ }^{\circ} \mathrm{C}\right.$ for $\left.\mathrm{AB}-\mathrm{PBI}\right)$.

5-6 mol PA per repeating unit of PBI. ${ }^{22}$ Higher doping levels increase the membrane conductivity; however the mechanical strength is weakened. ${ }^{23}$

Cross-linked blend membranes require higher doping temperatures because at room temperature the acid uptake is negligible. Fig. 9 shows the weight increase of the cross-linked membranes after immersion in PA at $130{ }^{\circ} \mathrm{C}$ until the weight was constant.

As reference the acid uptake of a commercial AB-PBI membrane (fumapem AM, Fumatech) after a previously optimised doping process $\left(6 \mathrm{~h}, 120^{\circ} \mathrm{C}\right)$ is presented. In contrast to the blend membranes, the AB-PBI membrane partly dissolved at $130{ }^{\circ} \mathrm{C}$, and the colour of the acid changed into slightly brown which resulted in low mechanical strength and decreased membrane conductivity. ${ }^{\mathbf{2 4}}$ The acid-base blend membranes are stabilized by the ionic crosslinking network.

Except of the covalently cross-linked base-base blend membrane MJK1844, the acid uptake of the blend membranes was lower as for the AB-PBI membrane despite the higher doping temperature. The comparison of the membranes MCS8X, MCS8Y and MCS8Z containing 50-70\% of the basic polymer PBIOO shows that the doping level correlates with the base content in the membrane. The reduction of the PBIOO content from $70 \%$ to $50 \%$ halves the acid uptake. Nevertheless the acidic polymer also has a major influence on the doping level as can be seen from the MKA membranes, which all contain $70 \% \mathrm{~F}_{6} \mathrm{PBI}$ though with different acidic polymers.

The required doping times to reach the equilibrium of the PA uptake are presented in Fig. 10. The doping time of almost all blend membranes was drastically shorter than that of AB-PBI. Except of the MJK1846 and the MKA018 membranes, the doping time of the blend membranes was a maximum of 2 hours. The covalently cross-linked base-base blend membrane MJK1844 reached a weight increase of almost $500 \%$ in 30 minutes due to the high amount of free basic nitrogen atoms in the polymer. 




Fig. 10 Doping time until membrane weight was constant.

\subsection{High frequency resistance and specific resistance}

The high frequency resistance (HFR) of the MEAs was measured in situ during fuel cell operation. The thickness of the membranes used for the MEA preparation was different, which is a critical parameter for IR losses in a fuel cell. Therefore the specific resistance (HFR divided by membrane thickness) of the membranes was calculated and is shown along with HFR in Fig. 11. The lowest HFR and specific resistance was achieved with the membranes MKA015 and MCS8Y.

The comparison between the relative HFR and specific resistance of the membranes shows that the HFR of the membranes MCS8Z, MKA016, MKA017, MKA050 and AB-PBI benefits from the relative low membrane thickness and especially the HFR of the membranes MJK1845 and MJK1846 is relatively high due to the higher membrane thickness.

In contrast to pure PBI membranes ${ }^{25}$ there was no direct correlation between the specific resistance and the PA uptake of the blend membranes. This might be due to the fact that



Fig. 11 High frequency resistance and specific resistance of the

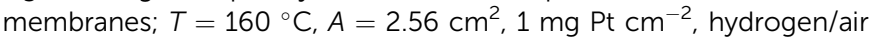
with $\lambda=1.4 / 2, j=200 \mathrm{~mA} \mathrm{~cm}^{-2}$.


Fig. 12 Cell performance of MEAs with different membranes; $T=$ $160^{\circ} \mathrm{C}, A=4 \mathrm{~cm}^{2}, 1 \mathrm{mg} \mathrm{Pt} \mathrm{cm}^{-2}, \lambda$ (hydrogen) $=1.4, \lambda$ (air) $=2$, ambient pressure.

PA-doped PBI-type HT-PEMFC membranes are very complex systems in which not only the absolute PA content is of importance, but also the PA distribution within the membrane matrix. $^{24}$ 
As an example for the complex dependence of membrane properties from membrane composition, a literature example is mentioned here: for cross-linked anion-exchange membranes from electrospun nanofibers it was observed that there is a complex interplay between swelling, cross-linking degree and ion conductivity: ${ }^{26}$ when the cross-linking degree of the membranes was increased, first their ionic conductivity increased because the membrane swelling was decreased, leading to a higher content of fixed charge groups per unit volume of water, although the ionomer fiber ion-exchange capacity (IEC), which is calculated at the basis of dry ionomer, decreased with the increase of cross-linking degree. Only after overstepping a particular cross-linking degree, the conductivity began to decrease.

In case of the MKA membranes which contain phosphin oxide building groups it was observed that the $\mathrm{P}=\mathrm{O}$ groups are good proton acceptors and therefore able to form strong hydrogen bonds, ${ }^{27,28}$ which could be responsible for the observed high PA doping degree of the MKA015. MEAs based on the membranes with the highest acid uptake (MJK1844 and AB-PBI) only showed average specific resistance values among the investigated membranes.

The amount of acidic and basic polymers in the membranes had a major influence on the specific resistance. The specific resistance of the membrane MCS8Y consisting of $60 \%$ PBIOO and $40 \%$ PCS10 was about three times lower than the specific resistance of the membranes MCS8X (70\% PBIOO, $30 \%$ PCS10) and MCS $8 Z$ ( $50 \%$ PBIOO, 50\% PCS10). It turns out that for the unexpected behaviour of these membranes many different and in part counteracting properties of the ternary membranes $\mathrm{PBI} /$ sulfonated polymer/PA are responsible, among them mass ratio between $\mathrm{PBI}$ and sulfonated polymer, type of PBI and of sulfonated polymer, ionical cross-linking density of blend membrane, hydrophilicity of the blendforming polymers, distribution of PA in the membranes, interactions between PA and polymer chain segments of the blend components, making prediction of the ternary

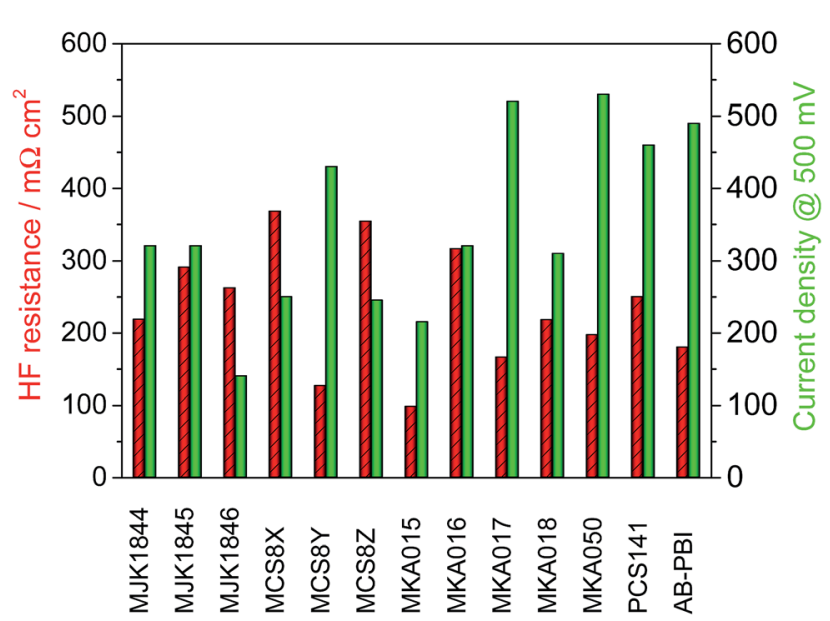

Fig. 13 High frequency resistance of the membranes and current density of the MEAs at $500 \mathrm{mV} ; T=160{ }^{\circ} \mathrm{C}, A=2.56 \mathrm{~cm}^{2}, 1 \mathrm{mg} \mathrm{Pt}$ $\mathrm{cm}^{-2}$, hydrogen/air with $\lambda=1.4 / 2$. membrane properties in dependence of these factors very difficult.

For clarification of the interplay between composition and properties of these membranes, many parameters of the membranes such as type of PBI, type and sulfonation degree of the sulfonated polymer, mass ratio between PBI and sulfonated blend component, PA doping degree, membrane thickness, and operation temperature would have to be varied. This is however beyond the scope of the present study which included screening of different PBI-excess acid-base blend membranes in terms of their suitability for application in HT-PEMFC application as a substitute for pure PBI membranes.

\subsection{Fuel cell performance}

The MEA performance is crucial for the application of membranes in fuel cells. Normalized application-oriented operation parameters were used for the cell tests to obtain comparable and practical relevant results. All MEAs were made of the particular membrane doped with PA and two electrodes consisting of $90 \%$ carbon supported platinum catalyst and $10 \%$ PTFE binder. The polarization curves, which are presented in Fig. 12, were measured at $160{ }^{\circ} \mathrm{C}$ and stoichiometries of 1.4 (hydrogen) and 2 (air). To simplify the comparison of the fuel cell performance, the measured current density at a cell potential of $500 \mathrm{mV}$ was extracted from the polarisation curves and is shown along with the HFR in Fig. 13.

The acid-base blend membranes MCS8Y, MKA017, MKA050, PCS141 and the AB-PBI membrane showed the highest MEA performance. The high MEA performance of the MCS8Y membrane can be explained with its very low HFR and the membranes with the highest HFR, MCS8X, MCS8Z and MKA016, showed a low MEA performance. However; no principal correlation between low HFR and high performance was observed.

The membranes MKA015 and MKA018 showed a low MEA performance despite low to average HFR values. The stiffness of both membranes was very high, even after doping with PA, which made it difficult to attach the electrodes to the membranes. This could have decreased the interface between membrane and electrodes leading to an increased chargetransfer resistance.

The polarisation curve of the membrane MKA015 showed a potential drop at $300 \mathrm{~mA} \mathrm{~cm}{ }^{-2}$ which indicated a mass transport problem in the electrodes. This is often caused by PA flooding of the electrodes and a simultaneous concentration decrease of the PA concentration in the surface layer of the membrane which might increase the interface resistance between membrane and electrodes and therefore lead to the observed potential drop of the polarization curve. Such behaviour might be prevented by adjusting the PTFE content in the electrodes..$^{29,30}$

The base-base blend membrane MJK1844 had the highest PA uptake after the shortest doping time which indicates that the doping temperature was too high for this membrane. Pure PBI dissolved in PA at a doping temperature of $130{ }^{\circ} \mathrm{C}$ and partial dissolution of AB-PBI membranes at these doping 
conditions was observed in a previous study, leading to reduced MEA performance. ${ }^{24}$ Optimizing of doping time and temperature similar to studies with AB-PBI membranes ${ }^{24}$ probably improves the MEA performance of the membrane MJK1844.

The thickness of the membranes MJK1845 and MJK1846 was relatively high compared to the other investigated membranes which led to high HFR despite low specific resistance values (Fig. 11).

\section{Conclusions}

In this study, novel acid-base blend membranes from the polybenzimidazoles $\mathrm{F}_{6} \mathrm{PBI}$, PBIOO and PBI HOZOL for application in HT-PEMFCs were synthesized and characterized. The blend membranes showed good thermal stability and drastically improved chemical stability compared to pure $\mathrm{PBI}$ and AB-PBI by means of weight loss during FT. Only small changes in the molecular weight distribution after immersion for 144 hours in Fenton's solution were detected with GPC. SEM images proved the outstanding integrity of the acid-base blend membranes.

Ionical cross-linking between the acid and base polymers not only enhanced the chemical stability but also the integrity of the membranes in hot PA. This resulted in higher conductivity of the blend membranes while maintaining reduced swelling. For example, the HF resistances of the blend membranes MCS8Y and MKA017 were lower than that of pure AB-PBI membranes although the acid uptake of the blend membranes was drastically reduced.

MEAs based on the novel blend membranes were prepared and evaluated in single cell tests at practical relevant conditions. The MEAs showed comparable fuel cell performance to state-of-the-art AB-PBI based MEAs for HT-PEMFCs despite the fact that the electrodes were not optimized for the novel blend membranes.

This study proves that acid-base blends are a suitable alternative to pure PBI and AB-PBI as membranes for HTPEMFCs. In future work the electrodes for the MEAs based on the blend membranes will be optimized to achieve higher cell performance than PBI or AB-PBI based MEAs. Particular attention will be given to the development of novel catalyst layers containing the blend polymers as binder to improve the threephase interlayer and the acid distribution in the electrodes.

Moreover, for the blend membranes MKA017, MKA050 and PCS141, which exhibited the best fuel cell performance, a detailed investigation of dependence of fuel cell performance from following parameters will be conducted: mass relation between PBI and sulfonated polymer and therefore ionic cross-linking degree, PA doping degree, membrane thickness, and operation temperature. It is expected that the results from this in-depth study will lead to a better understanding between composition and properties of PBI-based HT-PEMFC membranes.

\section{Acknowledgements}

The authors would like to acknowledge the financial support of the Impuls und Vernetzungsfonds der Helmholtz Gesellschaft (Young Investigator Group project VH-NG-616) and the DFG
(Deutsche Forschungsgemeinschaft - German Research Foundation) under project number KE 673/11-1 and Inna Kharitonova and Galina Schumski for the characterization work on the membranes.

\section{References}

1 J. S. Wainright, J.-T. Wang, D. Weng, R. F. Savinell and M. Litt, J. Electrochem. Soc., 1995, 142, L121-L123.

2 K.-D. Kreuer, S. J. Paddison, E. Spohr and M. Schuster, Chem. Rev., 2004, 104, 4637-4678.

3 S. Yu, L. Xiao and B. C. Benicewicz, Fuel Cells, 2008, 8, 165174.

4 R. Kuhn, J. Scholta, P. Krüger, C. Hartnig, W. Lehnert, T. Arlt and I. Manke, J. Power Sources, 2011, 196, 5231-5239.

5 J. Scholta, R. Kuhn, S. Wazlawik and L. Jörissen, ECS Trans., 2009, 17, 325-333.

6 J. H. Liao, Q. F. Li, H. C. Rudbeck, J. O. Jensen, A. Chromik, N. J. Bjerrum, J. Kerres and W. Xing, Fuel Cells, 2011, 11, 745755.

7 J. Kerres, A. Ullrich, F. Meier and T. Häring, Solid State Ionics, 1999, 125, 243-249.

8 J. Kerres, F. Schönberger, A. Chromik, T. Häring, Q. Li, J. O. Jensen, C. Pan, P. Noyé and N. J. Bjerrum, Fuel Cells, 2008, 8, 175-187.

9 Q. F. Li, H. C. Rudbeck, A. Chromik, J. O. Jensen, C. Pan, T. Steenberg, M. Calverley, N. J. Bjerrum and J. Kerres, J. Membr. Sci., 2010, 347, 260-270.

10 J. A. Kerres, A. Katzfuß, A. Chromik and V. Atanasov, J. Appl. Polym. Sci., 2014, 131, DOI: 10.1002/app.39889, article first published online: 18 SEP 2013.

11 F. Mack, M. Klages, J. Scholta, L. Jörissen, T. Morawietz, R. Hiesgen, D. Kramer and R. Zeis, J. Power Sources, 2014, 255, 431-438.

12 A. Panchenko, H. Dilger, E. Möller, T. Sixt and E. Roduner, J. Power Sources, 2004, 127, 325-330.

13 Z. Chang, H. Pu, D. Wan, L. Liu, J. Yuan and Z. Yang, Polym. Degrad. Stab., 2009, 94, 1206-1212.

14 Q. Li, J. O. Jensen, R. F. Savinell and N. J. Bjerrum, Prog. Polym. Sci., 2009, 34, 449-477.

15 Q. Li, R. He, J. O. Jensen and N. J. Bjerrum, Chem. Mater., 2003, 15, 4896-4915.

16 J. Lawrence and T. Yamaguchi, J. Membr. Sci., 2008, 325, 633640.

17 A. Chromik and J. A. Kerres, Solid State Ionics, 2013, 252, 140-151.

18 M. Han, G. Zhang, Z. Liu, S. Wang, M. Li, J. Zhu, H. Li, Y. Zhang, C. M. Lew and H. Na, J. Mater. Chem., 2011, 21, 2187.

19 J. J. Linares, C. Sanches, V. A. Paganin and E. R. González, J. Electrochem. Soc., 2012, 159, F194-F202.

20 Q. Li, C. Pan, J. O. Jensen, P. Noyé and N. J. Bjerrum, Chem. Mater., 2007, 19, 350-352.

21 H. Pu, L. Wang, H. Pan and D. Wan, J. Polym. Sci., Part A: Polym. Chem., 2010, 48, 2115-2122.

22 Q. Li, R. He, J. O. Jensen and N. J. Bjerrum, Fuel Cells, 2004, 4, 147-159. 
23 Q. Li, J. O. Jensen, C. Pan, V. Bandur, M. S. Nilsson, F. Schönberger, A. Chromik, M. Hein, T. Häring, J. Kerres and N. J. Bjerrum, Fuel Cells, 2008, 8, 188-199.

24 F. Mack, S. Heissler, R. Laukenmann and R. Zeis, J. Power Sources, 2014, 270, 627-633.

25 S. Bose, T. Kuila, T. X. H. Nguyen, N. H. Kim, K. Lau and J. H. Lee, Prog. Polym. Sci., 2011, 36, 813-843.

26 A. M. Park, F. E. Turley, R. J. Wycisk and P. N. Pintauro, Macromolecules, 2014, 47, 227-235.
27 S. Wang, Q. Ji, C. N. Tchatchoua, A. R. Shultz and J. E. Mcgrath, J. Polym. Sci., Part B: Polym. Phys., 1999, 37, 1849-1862.

28 S. Wang, J. Wang, Q. Ji, A. R. Shultz, T. C. Ward and J. E. McGrath, J. Polym. Sci., Part B: Polym. Phys., 2000, 38, 2409-2421.

29 F. Mack, T. Morawietz, R. Hiesgen, D. Kramer and R. Zeis, ECS Trans., 2013, 58, 881-888.

30 R. Zeis, Beilstein J. Nanotechnol., 2015, 6, 68-83. 